Pesq. Vet. Bras. 30(8):641-645, agosto 2010

\title{
Neosporose equina: ocorrência de anticorpos anti- Neospora spp. e associação entre status sorológico de éguas e de suas crias $^{1}$
}

\author{
Gustavo Toscan² ${ }^{*}$, Gustavo C. Cadore ${ }^{2}$, Roberta C.F. Pereira ${ }^{2}$, Gabriele B. \\ Silva², Alfredo S. Cezar², Luís A. Sangioni², Luis S. Segala de Oliveira ${ }^{3}$ \\ e Fernanda S.F.Vogel ${ }^{2}$
}

\begin{abstract}
Toscan G., Cadore G.C., Pereira R.C.F., Silva G.B., Cezar A.S., Sangioni L.A., Oliveira L.S.S. \& Vogel F.S.F. 2010. [Equine neosporosis: occurrence of antibodies against Neospora spp. and association between the serological status of the mares and of their offspring.] Neosporose equina: ocorrência de anticorpos anti-Neospora spp. e associação entre o status sorológico de éguas e de suas crias. Pesquisa Veterinária Brasileira 30(8):641-645. Departamento de Medicina Veterinánia Preventiva, Centro de Ciências Rurais, Universidade Federal de Santa Maria, Av. Roraima 1000, Prédio 44, Camobi, Santa Maria, RS 97105-900, Brazil. E-mail: gugatoscan@ hotmail.com

Neospora caninum and $N$. hughesi are protozoa which can infect horses and can cause reproductive and neurological diseases, respectively. The pathogenesis of neosporosis in horses is poorly understood, as well as the sources of horizontal infection of $N$. hughesi. Furthermore, there are doubts about the role of the vertical transmission of Neospora spp. in maintenance of these parasites in equine populations. In this study, we evaluated: (1) the occurrence of infections by Neospora spp. in a population of mares (in reproductive age) on a farm of Crioula breed horses; and (2) the possible association between the serological status of mares and of their offspring, aiming to investigate, indirectly, the relevance of transplacental transmission for the occurrence of Neospora spp. in these horses. We found a highly significant association between the serological status of mares and their offspring. Although had been exposed to the same environmental risk factors, the descendants of seropositive mares had a higher percentage of seropositivity against Neospora spp. compared to the descendants of seronegative mares. The association between kinship and serological status indicates an influence of vertical (transplacental) infection raising the occurrence of Neospora spp. in the studied equine population.
\end{abstract}

INDEX TERMS: Neospora caninum, Neospora hughesi, IFAT, transplacental transmission.

RESUMO.- Os protozoários Neospora caninum e N. hughesi infectam os equinos e podem provocar diferentes sinais clínicos associados a problemas reprodutivos ou a distúrbios neurológicos, respectivamente. A patogenia da neosporose é pouco conhecida nos equinos, bem como as fontes de infecção horizontal de N. hughesi. Além disso, há dúvidas quanto ao papel da transmissão vertical de Neospora spp. na sua manutenção

\footnotetext{
1 Recebido em 23 de outubro de 2009.

Aceito para publicação em 31 de março de 2010.

2 Departamento de Medicina Veterinária Preventiva, Centro de Ciências Rurais (CCR), Universidade Federal de Santa Maria (UFSM), Av. Roraima 1000, Prédio 44, Camobi, Santa Maria, RS 97105-900, Brasil. *Autor para correspondência: gugatoscan@ hotmail.com

${ }^{3}$ Hospital Veterinário, CCR, UFSM, Camobi , Santa Maria, RS.
}

em populações equinas. Neste estudo avaliaram-se: (1) a ocorrência da infecção por Neospora spp. na população de éguas em idade reprodutiva em um haras de cavalos da raça Crioula; $\mathrm{e}$ (2) a possível associação entre o status sorológico destas éguas com o de suas crias, como meio de investigar, indiretamente, a relevância da transmissão transplacentária na ocorrência da infecção por Neosporaspp. nestes animais. A associação entre o status sorológico das éguas e o de suas crias foi altamente significativa. Os animais descendentes de éguas soropositivas tiveram maior ocorrência de anticorpos anti-Neospora spp. do que os descendentes de éguas soronegativas, embora expostos aos mesmos fatores de risco ambientais. A associação entre parentesco em primeiro grau e status sorológico indica a influência da infecção vertical (transplacentária) na ocorrência de $\mathrm{Ne}$ ospora spp. na população equina estudada. 
TERMOS DE INDEXAÇÃO: Nesospora caninum, Neospora hughesi, RIFI, transmissão transplacentária.

\section{INTRODUÇÃO}

A neosporose tem grande importância em bovinos, e sua patogênese neste hospedeiro, em termos gerais, está esclarecida, porém, em equídeos, esta é pobremente conhecida (Lindsay 2001, Hoane et al. 2006, Dubey et al. 2007). Existem duas espécies de protozoários do gênero Neospora que infectam equinos, Neospora caninume Neospora hughesi(Apicomplexa, Sarcocystidae), sendo que a infecção por $N$. caninum tem sido associada a problemas reprodutivos e doença neonatal, e a infecção por N. hughesia distúrbios neurológicos (Lindsay 2001, Kligler et al. 2007, Veronesi et al. 2008).

Depois do relato inicial, em cães da Noruega (Bjerkas et al. 1984), N. caninum tem sido descrito em várias espécies de animais (Dubey \& Lindsay 1996, Gondim 2006). O $N$. hughesi foi descrito por Marsh et al. (1998), os quais isolaram o protozoário de um equino que apresentava sinais compatíveis com a mieloencefalite protozoária (EPM). Esta descoberta estabeleceu o N. hughesi como mais um potencial agente etiológico da EPM, aumentando a importância do diagnóstico de Neospora spp. em equinos.

O ciclo biológico de $N$. hughesi ainda não foi totalmente esclarecido. O hospedeiro definitivo é desconhecido, assim como outros possíveis hospedeiros intermediários, que não os equídeos (Hoane et al. 2006). Por consequência, ainda não se confirmou a rota natural da infecção horizontal por $N$. hughesi nestes animais. $N$. caninum, por sua vez, tem cães e coiotes como hospedeiros definitivos (McAllister et al. 1998, Gondim et al. 2004) e várias espécies como hospedeiros intermediários (Dubey \& Lindsay 1996, Gondim 2006). Em bovinos e caninos a transmissão transplacentária apresenta papel de destaque na perpetuação deste agente na população (Dubey et al. 2007). Com isso, pode-se supor que a transmissão vertical de Neospora spp., da égua gestante para o feto, esteja envolvida na manutenção do protozoário em populações equinas, considerando-se que a infecção congênita pode resultar no nascimento de animais persistentemente infectados (Locatelli-Dittrich et al. 2006).

A ocorrência da infecção transplacentária em éguas prenhes foi demonstrada por Dubey \& Porterfield (1990) que detectaram taquizoítos de $N$. caninum no pulmão de um feto equino abortado. No entanto, existem poucas informações sobre a ocorrência, a frequência e as consequências clínicas destes casos (Pitel et al. 2003, Veronesi et al. 2008), o que não esclarece a relevância da infecção transplacentária em populações equinas.

Tendo em vista a escassez de dados da infecção por Neospora spp. e das consequências da presença deste agente em populações equinas do Brasil, este estudo visou avaliar a ocorrência da infecção por este protozoário em um haras de cavalos Crioulos e investigar uma possível associação entre o status sorológico das éguas e o das suas crias, como consequência de uma possível ocorrência de transmissão vertical por este protozoário em equinos.

\section{MATERIAL E MÉTODOS}

\section{Desenho experimental}

Este estudo foi dividido em duas etapas: (1) determinação da ocorrência da infecção pelo Neospora spp. em uma população de equinos e (2) investigação de possível associação entre o status sorológico das éguas e o das suas crias nesta população.

Determinação da ocorrência da infecção por Neospora spp. nas éguas. Para a pesquisa de anticorpos anti-Neospora spp. foram utilizadas 116 éguas da raça Crioula em idade reprodutiva, as quais representaram $50 \%$ do total das éguas em reprodução do haras. As éguas foram incluídas neste estudo de forma aleatória, independentemente de histórico de problemas reprodutivos e/ou neurológicos.

Avaliação da associação entre o status sorológico das éguas e o de suas crias. Avaliou-se, indiretamente, a probabilidade de ocorrência da infecção vertical por Neospora spp. na população equina. Para isto, selecionaram-se as éguas das quais se tinha acesso a descendentes na propriedade. Assim, 12 éguas puderam ser utilizadas dentro do grupo das soropositivas e outras 12 foram selecionadas, por meio de sorteio, entre o grupo das soronegativas. Foram coletadas amostras de soro de descendentes destas 24 fêmeas, totalizando 24 amostras, 16 de fêmeas e 8 de machos. Amostras de potros (com até dez meses de idade) não foram coletadas pela possível interferência dos anticorpos da imunidade passiva.

\section{Coleta e preparação das amostras}

As amostras de sangue foram coletadas por punção da veia jugular com auxilio de vacuntainer. Após retração do coágulo, o soro foi recolhido e estocado a $-20^{\circ} \mathrm{C}$ até ser testado.

\section{Diagnóstico sorológico}

A pesquisa de anticorpos anti-Neospora spp. foi realizada através da técnica de imunofluorescência indireta (RIFI). Para isto, foram utilizadas lâminas de microscopia contendo taquizoítos de Neospora caninum da cepa NC-1, fixados por metanol. Para a realização da RIFI, as amostras de soro, diluídas em PBS (1:50), foram empregadas como anticorpo primário, aplicadas sobre as lâminas e incubadas por 30 minutos a $37^{\circ} \mathrm{C}$. Depois disso, foi adicionada à reação a anti-IgG( equina conjugada com a fluoresceína ${ }^{4}$ (anticorpo secundário), seguido de incubação por $30 \mathrm{~min}$. a $37^{\circ} \mathrm{C}$ em câmara escura.

Foram consideradas positivas aquelas amostras para as quais os taquizoítos apresentaram fluorescência periférica total (Paré et al. 1995), e negativas as amostras em que houve fluorescência parcial e apical ou em que não houve fluorescência. Amostras de soro positivas na diluição de 1:50 foram submetidas a titulação dos anticorpos pela RIFI para a determinação do título máximo da reação.

\section{Análise estatística}

As comparações entre o status sorológico das éguas com o de suas crias (Quadro 1) foram analisadas utilizando-se 0 teste do Qui-quadrado.

\section{RESULTADOS E DISCUSSÃO}

A ocorrência de Neospora spp. na população de fêmeas em idade reprodutiva do haras foi de 13,8\% (16/116), com

\footnotetext{
${ }^{4}$ Goat Anti-Equine IgG (H+L)-FITC, 160A Oxmoor Blvd, Birmingham, AL 35209, USA. www.southernbiotech.com
} 
Quadro 1. Anticorpos (Ac) anti-Neospora spp. em fêmeas equinas $(E)$ da raça Crioula (1 $1^{\text {a }}$ geração) e em suas respectivas crias (C) ( $2^{\mathrm{a}}$ geração), detectados através da reação de imunofluorescência indireta (RIFI)

\begin{tabular}{|c|c|c|c|c|c|}
\hline $\begin{array}{c}1^{\text {a }} \\
\text { geração }\end{array}$ & $\begin{array}{l}\text { RIFI } \\
(+/-)^{\mathrm{a}}\end{array}$ & $\begin{array}{l}\text { Título } \\
\text { de } A c^{b}\end{array}$ & $\begin{array}{c}2^{\underline{a}} \\
\text { geração }\end{array}$ & $\begin{array}{l}\text { RIFI } \\
(+/-)^{\mathrm{a}}\end{array}$ & $\begin{array}{l}\text { Título } \\
\text { de } A c^{b}\end{array}$ \\
\hline \multicolumn{3}{|c|}{ Éguas soropositivas } & \multicolumn{3}{|c|}{ Crias de éguas soropositivas } \\
\hline E 01 & + & 800 & C 01 & + & 800 \\
\hline E 02 & + & 800 & C 02 & + & 50 \\
\hline E 03 & + & 800 & C 03 & + & 200 \\
\hline E 04 & + & 50 & C 04 & + & 400 \\
\hline E 05 & + & 100 & C 05 & - & 0 \\
\hline E 06 & + & 50 & C 06 & - & 0 \\
\hline E 07 & + & 50 & C 07 & - & 0 \\
\hline E 08 & + & 800 & C 08 & - & 0 \\
\hline E 09 & + & 800 & C 09 & + & 100 \\
\hline E 10 & + & 800 & C 10 & + & 50 \\
\hline E 11 & + & 800 & C 11 & + & 50 \\
\hline E 12 & + & 800 & C 12 & + & 100 \\
\hline \multicolumn{3}{|c|}{ Fêmeas soronegativas } & \multicolumn{3}{|c|}{ Crias de éguas soronegativas } \\
\hline E 13 & - & 0 & C 13 & - & 0 \\
\hline E 14 & - & 0 & C 14 & + & 50 \\
\hline E 15 & - & 0 & C 15 & - & 0 \\
\hline E 16 & - & 0 & C 16 & - & 0 \\
\hline E 17 & - & 0 & C 17 & - & 0 \\
\hline E 18 & - & 0 & C 18 & - & 0 \\
\hline E 19 & - & 0 & C 19 & - & 0 \\
\hline E 20 & - & 0 & C 20 & - & 0 \\
\hline E 21 & - & 0 & C 21 & - & 0 \\
\hline E 22 & - & 0 & C 22 & - & 0 \\
\hline E 23 & - & 0 & C 23 & - & 0 \\
\hline E 24 & - & 0 & C 24 & - & 0 \\
\hline
\end{tabular}

a Resultado da detecção de anticorpos anti-Neospora spp. pela técnica de RIFI, triagem na diluição de 1:50. Resultado dos animais: positivo (+) ou negativo (-).

b Titulação dos anticorpos anti-Neospora spp em equinos após resultado da triagem.

título de anticorpos variando de 50 a 800 . Conforme demonstrado por Gondim et al. (2009), deve-se suspeitar de um alto percentual de reatividade sorológica cruzada entre $N$. caninum e $N$. hughesi, o que não permite a diferenciação da infecção por estes agentes utilizando-se a RIFI ou outros testes correlatos. Dessa forma, embora se tenham utilizado taquizoítos de Neospora caninum na RIFI, considera-se a ocorrência para o gênero Neospora spp. devido à especificidade insuficiente da reação.

A ocorrência detectada no presente estudo pode ser considerada alta, se comparada a outras pesquisas conduzidas no Brasil: Dubey et al. (1999) pesquisaram anticorpos em amostras de soro de equinos do Brasil por meio de um teste de aglutinação direta (NAT), e não detectaram anticorpos anti-Neospora spp.; enquanto Hoane et al. (2006) encontraram uma prevalência de $2,5 \%$ utilizando um teste ELISA, em um estudo amplo, que abrangeu uma amostragem aleatória, e não padronizada, de soros equinos de diversas regiões do País.

Embora Villalobos et al. (2006) tenham demonstrado ocorrência de 10,3\% de anticorpos contra Neospora spp. em amostras de soro de equinos provenientes do estado de São Paulo, Brasil, deve-se ponderar que boa parte dos ani- mais incluídos nesse estudo apresentava histórico de problemas reprodutivos e, considerando-se apenas o grupo de fêmeas com tais problemas, como abortos no terceiro trimestre gestacional ou mortalidade neonatal, a positividade para o agente elevou-se para 15,1\%. Comprovando esta associação, em Israel, Kligler et al. (2007) encontraram maior prevalência de Neospora spp. em éguas que passaram por episódios de aborto e em cavalos com distúrbios neurológicos se comparados a equinos assintomáticos.

Por outro lado, alta prevalência de Neospora spp. foi observada por Locatelli-Dittrich et al. (2006), chegando a até $47 \%$ em uma população equina no estado do Paraná, Brasil. Contudo, no monitoramento sorológico desses animais observaram-se variações significativas deste índice em diferentes períodos e/ou com diferentes diluições (1:50 e 1:100) de soro.

No que diz respeito à análise da relação entre o status sorológico das éguas e o das suas crias, os resultados encontram-se descritos no Quadro 1. A metodologia utilizada, obviamente, não permite a comprovação de infecção vertical. No entanto, observou-se uma relação altamente significativa $(p=0,0032)$ entre o status sorológico das éguas e o das suas crias. Detectaram-se anticorpos anti- $N$. caninum em $8,3 \%$ (1/12) dos descendentes das éguas soronegativas. Por outro lado, quando avaliados os descendentes de éguas soropositivas este índice elevouse para $66,7 \%$ (8/12). Na comparação dos percentuais de soropositividade da população total de éguas adultas estudada $(13,8 \%)$ com a população de descendentes de éguas soropositivas presentes no haras $(66,7 \%)$ também se detectou uma diferença altamente significativa $(p<0,0001)$. Estes dados revelam que as crias de éguas soropositivas apresentam maior índice de soropositividade em relação às crias de éguas soronegativas, provavelmente pela ocorrência da infecção transplacentária.

Dubey \& Porterfield (1990) e Locatelli-Dittrich (2002) detectaram Neospora spp. em fetos equinos abortados, mas a associação da neosporose com perda fetal tem se demonstrado inconsistente (McDole \& Gay 2002, Villalobos et al. 2006, Kligler et al. 2007, Veronesi et al. 2008). Hoffmann (2007) avaliou a possibilidade de transmissão transplacentária utilizando éguas positivas para Neospora spp., sendo que não foram detectados anticorpos contra o protozoário em amostras coletadas pré-colostro em nenhuma de suas crias. Por outro lado, Locatelli-Dittrich et al. (2006) detectaram anticorpos contra este protozoário em potros desprovidos de colostro, e Veronesi et al. (2008) encontraram correlação significativa entre a presença do DNA de $N$. caninum em tecidos cerebrais e a ocorrência de abortos ou potros natimortos, porém, não obtiveram a comprovação de manifestações patológicas do protozoário nos tecidos destes animais.

As diferenças encontradas nesses estudos demonstram que as consequências provocadas pela infecção transplacentária por Neospora spp. em equinos podem ser consideradas imprevisíveis, dentro de uma gama de possibilidades que vai desde a ausência de sinais clínicos até a 
morte ou a inviabilidade fetal. Com isso, também é de se esperar que a transmissão vertical ocorra de forma variável (ou intermitente) a cada gestação de uma égua.

Em condições naturais, essa variabilidade pode decorrer de: as fêmeas gestantes serem primíparas ou não, de estarem sendo submetidas a uma primoinfecção ou à reativação da parasitemia, ao nível de parasitemia que se estabeleça, à fase da gestação em que se dê a infecção ou a reativação, ao nível de competência imunológica em que se encontre o feto, entre outros (Lindsay 2001, Dubey et al. 2007). Estes fatores irão interferir na eficiência da passagem transplacentária dos taquizoítos e nas consequências de uma eventual infecção dos tecidos fetais no curso da gestação. Seguindo-se esta linha de raciocínio, é perfeitamente aceitável que éguas soropositivas tenham crias soronegativas. Além disso, devese ressaltar que, caso o título de anticorpos séricos esteja abaixo do ponto de corte estabelecido para o estudo no momento da coleta de sangue, estes animais, embora soropositivos, acabam não sendo detectáveis. Assim, a ocorrência de animais soropositivos, filhos de éguas soronegativas, pode dever-se à infecção horizontal. No entanto, mesmo nestes casos, não se pode excluir a participação de infecção vertical, sabendo-se que a resposta imune desenvolvida pelos animais ao Neospora spp. é de curta duração e não é suficientemente efetiva para evitar a formação de cistos teciduais, a reativação dos parasitas e a ocorrência de infecção transplacentária (Innes et al. 2002). Neste sentido, o baixo nível de resposta imune, poderia, inclusive, facilitar a infecção vertical.

Contudo, deve-se ressaltar que a ocorrência de infecção transplacentária não estará, necessariamente, relacionada à ocorrência de distúrbios reprodutivos em uma população equina, portanto, devem-se considerar os diversos fatores epidemiológicos que poderão interferir nesta relação de causa e efeito. Comprovando esta hipótese, Villalobos et al. (2006) constataram que houve uma relação entre a presença de anticorpos contra Neospora spp. no soro sanguíneo de éguas e o seu histórico de desordens reprodutivas, enquanto na pesquisa desenvolvida por Hoffmann (2007) esta relação não foi observada.

\section{CONCLUSÕES}

A frequência de detecção de anticorpos anti-Neospora spp. encontrada no presente estudo demonstra que este protozoário esta disseminado na população equina estudada e, consequentemente, poderá resultar em sinais clínicos de ordem reprodutiva e/ou neurológica.

A relação entre parentesco e status sorológico indica que a transmissão vertical tem importância na manutenção de $N$. caninum e no aumento da sua prevalência na população equina, uma vez que, embora sob as mesmas condições ambientais, expostos aos mesmos fatores de risco em relação à transmissão horizontal, os descendentes de fêmeas positivas apresentam maior soropositividade.

Embora o presente estudo tenha demonstrado uma relação altamente significativa entre a sorologia das mães e dos seus descendentes, o que sugere fortemente a ocorrência de infecção transplacentária, novos experimentos devem ser conduzidos para determinar com clareza a patogenia e as consequências desta infecção em equinos. Estudos utilizando tanto éguas naturalmente infectadas como inoculadas experimentalmente e seus respectivos potros, antes da ingestão do colostro, devem ser conduzidos. Além disso, é necessário que se avaliem as consequências da infecção transplacentária em diferentes fases gestacionais. Ainda, estudos visando o desenvolvimento de técnicas sorológicas que permitam a diferenciação entre anticorpos anti- $N$. hughesi e anti- $N$. caninum precisam ser empreendidos para possibilitar a compreensão da patogenia da infecção por estas duas espécies.

Agradecimentos.- Ao professor José Henrique Souza da Silva, do Departamento de Zootecnia da UFSM, pelo auxílio na análise estatística dos dados, e aos professores Rudi Weiblen e Eduardo Furtado Flores, pela cessão de estrutura e equipamentos do Setor de Virologia da UFSM, possibilitando a realização deste trabalho.

\section{REFERÊNCIAS}

Bjerkas I., Mohn S.F. \& Presthus J. 1984. Unidentified cyst-forming Sporozoon causing encephalomyelitis and myositis in dogs. Z. Parasitenkd. 70:271-274.

Dubey J.P. \& Lindsay D.S. 1996. A review of Neospora caninum and neosporosis. Vet. Parasitol. 67(1-2):1-59.

Dubey J.P. \& Porterfield M.L. 1990. Neospora caninum (Apicomplexa) in an aborted equine fetus. J. Parasitol. 76(5):732-734.

Dubey J.P., Kerber C.E. \& Granstrom D.E. 1999. Serologic prevalence of Sarcocystis neurona, Toxoplasma gondii and Neospora caninum in horses in Brazil. J. Am. Vet. Med. Assoc. 215:970-972.

Dubey J.P., Schares G. \& Ortega-Mora L.M. 2007. Epidemiology and control of neosporosis and Neospora caninum. Clin. Microbiol. Rev. 20(2):323-367.

Gondim L.F.P. 2006. Neospora caninum in wildlife. Trends Parasitol. 22(6):247-252.

Gondim L.F.P., McAllister M.M., Pitt W.C. \& Zemlicka D.E. 2004. Coyotes (Canis latrans) are definitive hosts of Neospora caninum. Int. J. Parasitol. 34(2):159-161.

Gondim L.F.P., Lindsay D.S. \& McAllister M.M. 2009. Canine and bovine Neospora caninum control sera examined for cross-reactivity using Neospora caninum and Neospora hughesi Indirect Fluorescent Antibody Tests. J. Parasitol. 95(1):86-88.

Hoane J.S., Gennari S.M., Dubey J.P., Ribeiro M.G., Borges A.S., Yai L.E.O., Aguiar D.M., Cavalcante G.T., Bonesi G.L. \& Howe D.K. 2006. Prevalence of Sarcocystis neurona and Neospora spp. infection in horses from Brazil based on presence of serum antibodies to parasite surface antigen. Vet. Parasitol. 136(2):155-159.

Hoffmann D.C.S. 2007. Cinética, avaliação da transmissão vertical e monitoramento da transferência passiva de anticorpos anti-Neospora sp. em equinos. Dissertação de Mestrado em Ciências Veterinárias, Universidade Federal do Paraná, Curitiba, PR. 91p.

Innes E., Andrianarivo A., Björkman C., Williams D.J. \& Conrad P. 2002. Immune responses to Neospora caninum and prospects for vaccination. Trends Parasitol. 18:497-504.

Kligler E.B., Shkap V., Baneth G., Mildenberg Z. \& Steinman A. 2007. Seroprevalence of Neospora spp. among asymptomatic horses, aborted mares and horses demonstrating neurological signs in Israel. Vet. Parasitol. 148:109-113.

Lindsay D.S. 2001. Neosporosis: An emerging protozoal disease of horses. Equine Vet. J. 33(2):116-118.

Locatelli-Dittrich R. 2002. Diagnóstico sorológico, isolamento, cultivo e caracterização molecular de Neospora caninum em bovinos lei- 
teiros e em equinos no Estado do Paraná, Brasil. Tese de Doutorado em Tecnologia, Universidade Federal do Paraná, Curitiba, PR. $184 p$.

Locatelli-Dittrich R., Dittrich J.R., Richartz R.R.T.B., Gasino Joineau M.E., Antunes J., Pinckney R.D., Deconto I., Hoffmann D.C.S. \& Thomaz-Soccol V. 2006. Investigation of Neospora spp. and Toxoplasma gondii antibodies in mares and in precolostral foals from Paraná state, Southern Brazil. Vet. Parasitol. 135(3/4):215-221.

Marsh A.E., Barr B.C., Packham A.E. \& Conrad P.A. 1998. Description of a new Neospora species (Protozoa: Apicomplexa: Sarcocystidae). J. Parasitol. 84(5):983-991.

McAllister M.M., Dubey J.P., Lindsay D.S., Jolley W.R., Wills R.A. \& McGuire A.M. 1998. Dogs are definitive hosts of Neospora caninum. Int. J. Parasitol. 28(9):1473-1478.

McDole M.G. \& Gay J.M. 2002. Seroprevalence of antibodies against Neospora caninum in diagnostic equine serum samples and their possible association with fetal loss. Vet. Parasitol. 105(3):257260.

Paré J., Hietala S.K., Thurmond M.C. 1995. Interpretation of an indirect fluorescent antibody test for diagnosis of Neospora sp. infection in catlle. J. Vet. Diag. Investig. 7(2):273-275.

Pitel P.H., Romand S., Pronost S., Foucher N., Gargala G., Maillard K., Thulliez P., Collobert-Laugier C., Tainturier D., Fortier G. \& Ballet J.J. 2003. Investigation of Neospora sp. antibodies in aborted mares from Normandy, France. Vet. Parasitol. 118:1-6.

Veronesi F., Diaferia M., Mandara M.T., Marenzoni M.L., Cittadini F. \& Fioretti D.P. 2008. Neospora spp. infection associated with equine abortion and/or stillbirth rate. Vet. Res. Commun. 32(1):223-226.

Villalobos E.M.C., Ueno T.E.H., Souza S.L.P., Cunha E.M.S., Lara M. C.C.S.H., Gennari S.M. \& Soares R.M. 2006. Association between the presence of serum antibodies against Neospora spp. and fetal loss in equines. Vet. Parasitol. 142(3/4):372-375. 